\title{
Mechanical and Microstructural Features of Ceramic Hollow Spheres
}

\author{
Alexandra KEMÉNY1,2, a, Dóra KÁROLY1,2, b \\ ${ }^{1}$ Budapest University of Technology and Economics, Faculty of Mechanical Engineering, Department of \\ Materials Science and Engineering, Budapest, Hungary \\ ${ }^{2}$ MTA-BME Lendület Composite Metal Foams Research Group, Budapest, Hungary \\ aalexa@eik.bme.hu \\ ${ }^{b}$ kdora@eik.bme.hu
}

\begin{abstract}
In this study two different types of hollow sphere were examined by mechanical, geometrical and microstructural measurements, and the fracture force, geometrical properties and chemical composition were determined. The diameter of the „01 globocer” type specimens was $2.37 \mathrm{~mm}$ on average, while the value for the „03 globocer” type specimens was $6.88 \mathrm{~mm}$, both were smaller than the nominal diameter. The average deviation from the circularity of the 01 globocer specimens was $8 \%$, the value for the 03 globocer specimens was $6 \%$, while the average wall porosity was $53 \pm 3 \%$ and $56 \pm 3 \%$ respectively. The surface of the hollow spheres was uneven, which has an impact on the contact surfaces during pressure tests, which affects the fracture force values. The average value of the fracture force of 01 globocer spheres was $42 \mathrm{~N}$, and of 03 globocer hollow spheres was $288 \mathrm{~N}$. The diameter had a bigger impact on the fracture force values of the type 01 specimens than in the case of 03.
\end{abstract}

Keywords: ceramic hollow sphere, metal foam, mechanical properties.

\section{Introduction}

Nowadays the reduction of a components' mass with the enhancement of specific mechanical properties plays a primary role in industrial applications. Materials design methods are increasingly focusing on lightweight materials considering energy efficiency and the best value for money. Increasing the specific resistance of the structure or the equipment to compressive loads can be achieved by using lower density and higher strength materials, to which closed cellular metal foams provide one of the best solutions. This composite material is mainly used in vehicles as an energy absorber or sandwich panel [1].

Metal matrix syntactic foams (MMSFs) are a special type of closed cell foams, where the porosity inside the metallic matrix is ensured by a second phase or filling material. Various matrix and filler materials are investigated in the literature, but the most common type of the latter is the ceramic hollow sphere, which can be made from mixed oxide ceramics [2, 3], high purity and quality alumina [4, 5] or silicon carbide [6, 7]. There are experiments in using metallic hollow spheres [8] or expanded perlite $[9,10]$ too. Syntactic foams made with these spheres have excellent specific energy absorbing properties and compressive strength, but their price is relatively high [11].

The properties of the filler materials alone are a poorly researched area, although they have a great impact on the produced metal foams' properties. Dong et al., and Ruan et al. investigated the fracture mechanisms of thin-walled hollow spheres during dynamical compression tests. Both groups made compression measurements with different sized compression tools and different strain rates. They reported that the load speed greatly affects the mode of the failure [12, 13]. 
Song et al. examined the microstructure and failure methods of metallic hollow spheres with both experimental and finite element methods. The different distribution of microporosity in the sphere walls resulted in diverse failure modes in each case [14].

Since there are only a few studies available on the subject, and as other research groups have investigated the compression behaviour of material hollow spheres other than ceramic, this research aims at to investigate the geometrical, microstructural and mechanical properties of two commonly used ceramic hollow sphere types.

\section{Materials and methods}

Two types of ceramic hollow spheres were tested (Figure 1.) from Hollomet during the research. From both types, 50-50 different pieces were examined for various mechanical, geometrical and microstructural properties.

The nominal material type, bulk density and diameter of the investigated hollow spheres are shown in Table 1.

First, the diameter of the samples was measured using a Mitutoyo Absolute Digimatic CD-15DC caliper, rotating the specimens to determine the average deviation from circularity. Then, the fracture measurement of the hollow spheres was performed at the rate of $0.1 \mathrm{~mm} / \mathrm{min}$ between two

Table 1. Data of the examined ceramic hollow spheres

\begin{tabular}{|l|c|c|c|}
\hline & Material & $\begin{array}{c}\boldsymbol{\rho} \\
\left(\mathbf{g} / \mathbf{c m}^{3}\right)\end{array}$ & $\begin{array}{c}\boldsymbol{\emptyset D}_{\mathbf{n}} \\
(\mathbf{m m})\end{array}$ \\
\hline 01 globocer & $\mathrm{Al}_{2} \mathrm{O}_{3} \mathrm{C} 795$ & 0,59 & 2,4 \\
\hline 03 globocer & $\mathrm{Al}_{2} \mathrm{O}_{3} \mathrm{C} 795$ & 0,60 & 7,0 \\
\hline
\end{tabular}

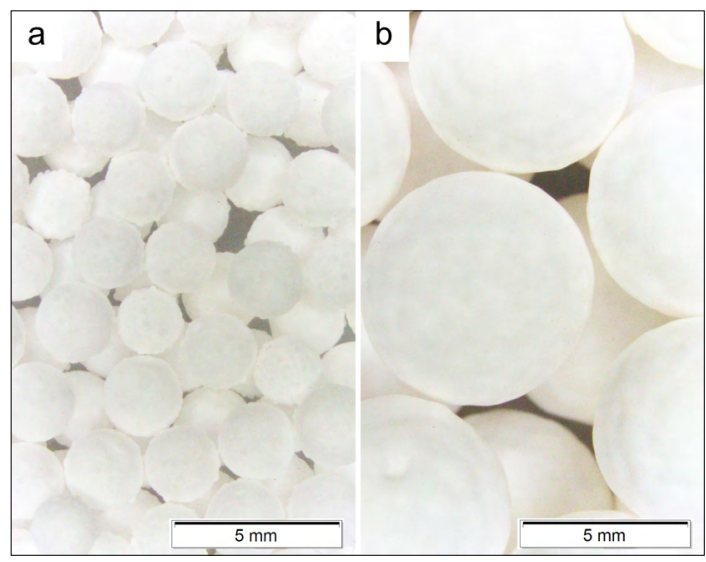

Figure 1. Macro image of the investigated hollow spheres: 01 globocer $\circledR(a)$ and 03 globocer $\circledR(b)$ flat plates (Figure 2.). The examination was performed with an Instron 5965 electromechanical universal material testing device.

Embedded in a two-component epoxy resin, the hollow spheres were polished up to their centerplane, so that the wall thickness, internal structure, porosity and the circularity of the samples were examined optically by Olympus SZX16 stereo and Olympus PMG-3 metallurgical microscopes. The deviation from circularity was determined by the formula (1), with the smallest and largest measured values $D_{\min }$ and $D_{\max }$ respectively.

$$
\frac{D_{\max }-D_{\min }}{\bar{D}} \cdot 100(\%)
$$

For further investigation of the morphology, a Zeiss EVO MA10 scanning electron microscope (SEM) was used, and the composition of the material was determined by the microscope EDAX energy dispersive X-ray spectrometry (EDS) module. Images were made with $20 \mathrm{kV}$ accelerating voltage and a secondary electron detector.

\section{Results}

The average $(\varnothing \overline{\mathrm{D}})$ and the standard deviation (s) of the measured diameters of the hollow spheres are shown in Table 2. It can be observed that the samples are smaller on average than the nominal size.

In addition to measuring the diameters with a calliper, the circularity of the samples and the thickness of the samples were measured using a stereomicroscope on the embedded and polished samples. As can be seen in Figure 3., the test samples, although close to circular, have uneven surfaces and wall thicknesses, which can have a

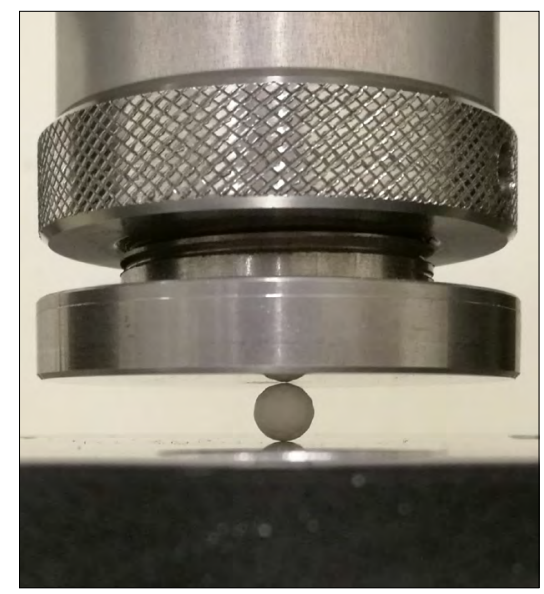

Figure 2. Mechanical testing layout 
major impact on their mechanical properties, depending on the direction of the load. The average deviation from the circularity of 01 globocer was $8 \%$ and that of 03 globocer was $6 \%$.

The average thickness of the wall measured with the microscope is $0.125 \mathrm{~mm}$ for 01 globocer and $0.346 \mathrm{~mm}$ for 03 globocer. The data can be used to calculate the average diameter factor resulting from the ratio of internal to external diameter (Table 3.).

Based on pressure infiltration technique, which results a $\sim 64 \%$ filling and homogeneous filler distribution using the random close-packing theory [15], the ratio of internal and external diameters and theoretical porosity $\left(\mathrm{P}_{\mathrm{FOAM}}\right)$ of metal foam can be calculated [16, 17].

The more accurate examination of surface morphology was possible by scanning electron microscopy (Figure 4.). Both types of ceramic hollow spheres have an uneven surface, but the smaller spheres are more uneven than the larger ones. The outer and inner surfaces of the hollow

Table 2. Diameter values of the examined hollow spheres

\begin{tabular}{|l|c|c|}
\hline & 01 globocer & 03 globocer \\
\hline$\emptyset \overline{\mathrm{D}}(\mathrm{mm})$ & 2,37 & 6,88 \\
\hline$\emptyset \mathrm{D}_{\text {min }}(\mathrm{mm})$ & 2,00 & 6,44 \\
\hline$\varnothing \mathrm{D}_{\text {max }}(\mathrm{mm})$ & 2,65 & 7,36 \\
\hline $\mathrm{s}(\mathrm{mm})$ & 0,13 & 0,22 \\
\hline
\end{tabular}

Table 3. The diameter ratio and theoretical porosity value of the examined hollow spheres

\begin{tabular}{|c|c|c|}
\hline & 01 globocer & 03 globocer \\
\hline$\varnothing \overline{\mathrm{d}}(\mathrm{mm})$ & 2,12 & 6,19 \\
\hline$\sum_{i=1}^{n} \frac{\varnothing \boldsymbol{d}_{i} / \varnothing \boldsymbol{D}_{i}}{n}$ & 0,90 & 0,90 \\
\hline $\mathrm{P}_{\mathrm{FOAM}}(\%)$ & 55 & 58 \\
\hline
\end{tabular}

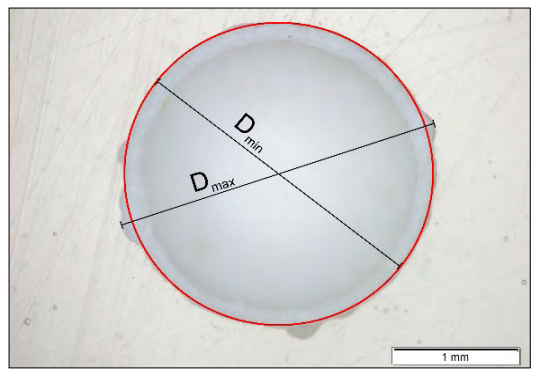

Figure 3. Cross section image of 03 globocer hollow sphere spheres are rough compared to their whole sizes.

The morphology of the internal porosity was observed on metallurgical microscopic images (Figure 5.), and on the fracture surface of the samples' walls (SEM) (Figure 6.).

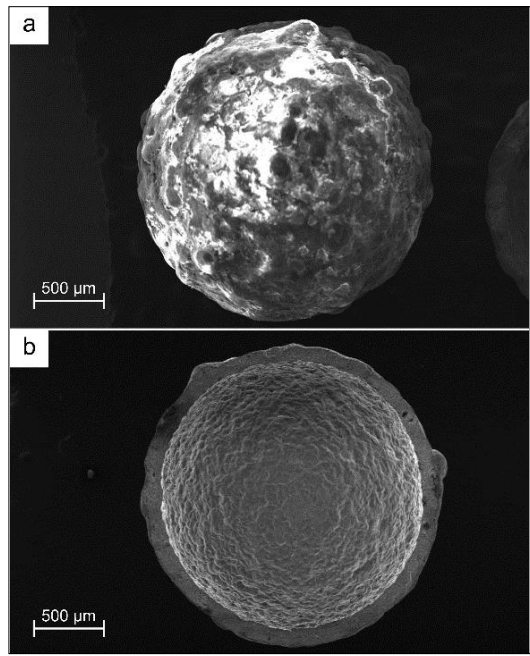

Figure 4. SEM image of the outer (a) and inner (b) surface of 01 globocer hollow sphere

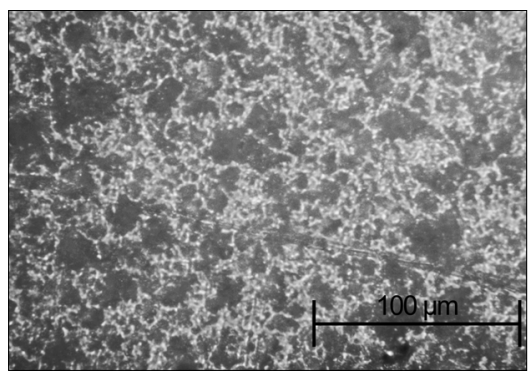

Figure 5. Metallurgical microscopic image of the wall of 03 globocer hollow sphere

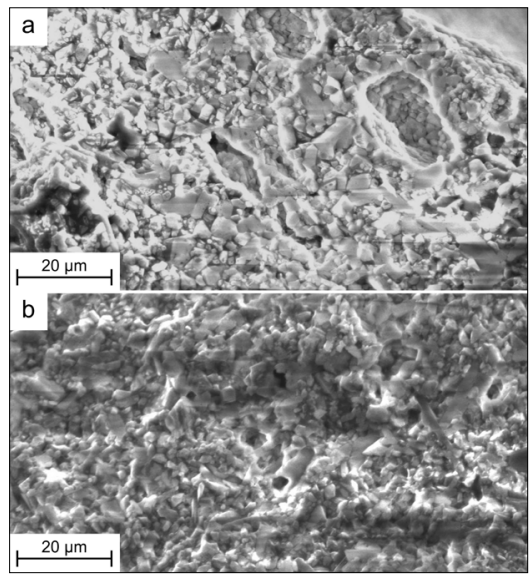

Figure 6. Inner porosity of 01 globocer (a) and 03 globocer (b) 
This shows that, although made of the same material, pores in the smaller diameter hollow spheres were larger than those found in the larger diameter hollow spheres. The total porosity was in opposition to this observation (for 01 globocer $53 \pm 3 \%$ and for 03 globocer $56 \pm 3 \%$ ).

In addition a part of the hollow spheres are not floating on the surface of the water, but sink beneath. This is caused by the high porosity of the walls.

The mechanical characterization of the hollow spheres was marked by the fracture force, because due to the unevenness of the wall thickness of the hollow spheres, an acceptable stress value could not be obtained. The fracture force is the maximal force measured during the compression tests.

Figures 7-8. show the fracture forces of the two different sample correlated to their diameter. It can be observed that in the smaller hollow spheres, the deviation of the diameter influences the force value associated with the failure; there is a correlation between the two values.

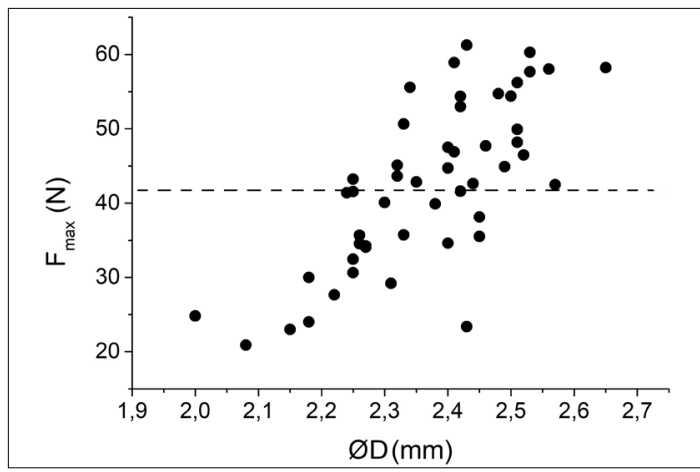

Figure 7. Fracture force of 01 globocer in correlation to the diameter values

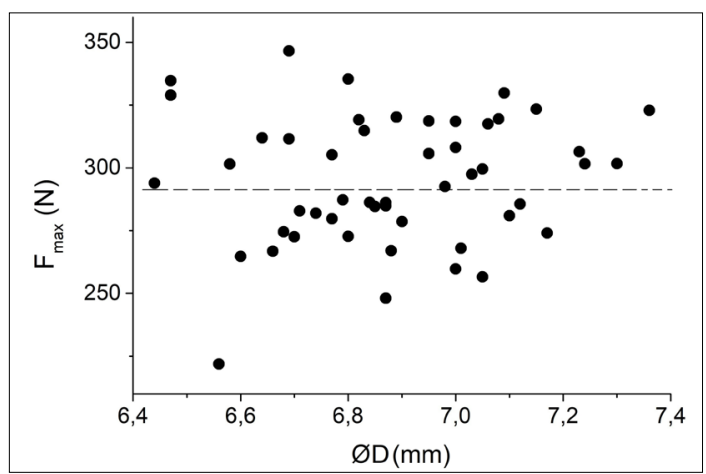

Figure 8. Fracture force of 03 globocer in correlation to the diameter values
Table 4. Composition of the examined hollow spheres

\begin{tabular}{|l|c|c|}
\hline & O (t\%) & Al (t\%) \\
\hline 01 globocer & $56 \pm 4$ & $42 \pm 3$ \\
\hline 03 globocer & $49 \pm 3$ & $50 \pm 5$ \\
\hline
\end{tabular}

Table 4. shows the composition of the aluminium oxide based ceramic hollow spheres measured by EDS measurement as the average of at least 3 different spots on one sample, on the total of 3 different samples' fracture surfaces from each type.

It can be observed that the measured average values show 97-99 wt\% aluminium and oxygen in the material. Also the spheres may contain $1 \%$ or less Si and Ca too. This value is in accordance with the IEC 60672-3:1997 standard and the manufacturer specified C795 material.

\section{Conclusions}

Overall, it can be stated that it is important to have measurement data on mechanical, geometrical and microstructural properties of the ceramic hollow spheres - which are often used as filler in metal foams - for engineering design purposes. The following observations were made during the research:

- the diameter of the 01 globocer specimens was $2.37 \mathrm{~mm}$ on average, while the value for the 03 globocer specimens was $6.88 \mathrm{~mm}$, both were smaller than the nominal diameter;

- the average deviation from circularity of the 01 globocer specimens was $8 \%$, the value for the 03 globocer specimens was $6 \%$;

- the surface of the hollow spheres was uneven, which has an impact on the contact surfaces during pressure tests, which affects the fracture force values;

- the average wall porosity of 01 and 03 globocer specimens was $53 \pm 3 \%$ and $56 \pm 3 \%$ respectively; - the average value of the fracture force of 01 globocer spheres was $42 \mathrm{~N}$, with the standard deviation of $12.5 \mathrm{~N}$, and of 03 globocer hollow spheres, the average was $288 \mathrm{~N}$, with the standard deviation of $41 \mathrm{~N}$;

- the diameter had a bigger impact on the fracture force values of the type 01 specimens than in the case of 03 ;

- and it can be stated that both sized ceramic hollow spheres' material is in accordance with the quality that manufacturer specified. 


\section{Acknowledgement}

The publication reported herein has been supported by the Gépészmérnök-képzésért Alapítvány.

\section{References}

[1] Gupta N., Rohatgi P. K.: 4.15 Metal Matrix Syntactic Foams. In: Comprehensive Composite Materials II. Elsevier, Oxford, 2018. 364-385. doi.org/10.1016/B978-0-12-803581-8.09971-9

[2] Szlancsik A., Katona B., Károly D., Orbulov I. N.: Notch (In)Sensitivity of Aluminum Matrix Syntactic Foams. Materials, 12/574. (2019) 15. doi.org/10.3390/ma12040574

[3] Zhang Q., Lee P. D., Singh R., Wu G., Lindley T. C.: Micro-CT characterization of structural features and deformation behavior of fly ash/aluminum syntactic foam. Acta Materialia 57. (2009) 3003-3011. doi.org/10.1016/j.actamat.2009.02.048

[4] Ferguson J. B., Santa Maria J. A., Schultz B. F., Rohatgi P. K.: $\mathrm{Al}_{-} \mathrm{Al}_{2} \mathrm{O}_{3}$ syntactic foams-Part II: Predicting mechanical properties of metal matrix syntactic foams reinforced with ceramic spheres. Materials Science and Engineering, A 582. (2013) 423-432.

doi.org/10.1016/j.msea.2013.06.065

[5] Omar M. Y., Xiang C., Gupta N. Strbik, O. M., Cho K.: Data characterizing flexural properties of $A V$ $\mathrm{Al}_{2} \mathrm{O}_{3}$ syntactic foam core metal matrix sandwich. Data Br, 5. (2015) 564-571. doi.org/10.1016/j.dib.2015.09.054

[6] Katona B., Szlancsik A., Tábi T., Orbulov I. N.: Compressive characteristics and low frequency damping of aluminium matrix syntactic foams. Materials Science and Engineering, 739. (2019) 140-148. doi.org/10.1016/j.msea.2018.10.014

[7] Cox J., Luong D. D., Shunmugasamy V. C., Gupta N., Strbik O. M., Cho K.: Dynamic and Thermal Properties of Aluminum Alloy A356/Silicon Carbide Hollow Particle Syntactic Foams. Metals, 4. (2014) 530-548. doi.org/10.3390/met4040530

[8] Pérez L., Villalobos M., Órdenes C., Drew R. A. L., Ruiz-Aguilar C., Alfonso I.: Elastic Modulus Estimation for Copper Syntactic Foams Reinforced with Iron Hollow Spheres of Different Wall Thicknesses. Journal of Materials Engineering and Performance, 28/1. (2019) 100-106.

doi.org/10.1007/s11665-018-3827-3
[9] Taherishargh M., Belova I. V., Murch G. E., Fiedler T.: The effect of particle shape on mechanical properties of perlite/metal syntactic foam. Journal of Alloys and Comppunds, 693. (2017) 55-60. doi.org/10.1016/j.jallcom.2016.09.168

[10] Fiedler T., Taherishargh M., Krstulovic-Opara L., Vesenjak M.: Dynamic compressive loading of expanded perlite/aluminum syntactic foam. Materials Science and Engineering, A, 626. (2015) 296-304. doi.org/10.1016/j.msea.2014.12.032

[11] Szlancsik A., Katona B., Orbulov I. N., Taherishargh M., Fiedler T.: Fatigue properties of EP/A356 aluminium matrix syntactic foams with different densities. IOP Conference Series: Materials Science and Engineering, 426. (2018) 8p. doi.org/10.1088/1757-899X/426/1/012045

[12] Dong X.L., Gao Z.Y., Yu T.X.: Dynamic crushing of thin-walled spheres: An experimental study. International Journal of Impact Engineering, 35/8. (2008) 717-726. doi.org/10.1016/j.ijimpeng.2007.11.004

[13] Ruan H. H., Gao Z. Y., Yu T. X.: Crushing of thinwalled spheres and sphere arrays. International Journal of Mechanical Science, 48/2. (2006) 117-133. doi.org/10.1016/j.ijmecsci.2005.08.006

[14] Song J., Sun Q., Luo S., Arwade S. R., Gerasimidis S., Guo Y., Zhang G.: Compression behavior of individual thin-walled metallic hollow spheres with patterned distributions of microporosity. Materials Science and Engineering A, 734. (2018) 453-475 doi.org/10.1016/j.msea.2018.08.016

[15] Finney J. L.: Random packings and the structure of simple liquids I. The geometry of random close packing. Royal Society of London A, 319/1539. (1970) 479-493. doi.org/10.1098/rspa.1970.0189

[16] Gupta N., Woldesenbet E., Mensah P.: Compression properties of syntactic foams: effect of cenosphere radius ratio and specimen aspect ratio. Composites Part A: Applied Science and Manufacturing, 35/1. (2004) 103-111. doi.org/10.1016/j.compositesa.2003.08.001

[17] Kiser M., He M. Y., Zok F. W.: The mechanical response of ceramic microballoon reinforced aluminum matrix composites under compressive loading. Acta Materialia, 47/9. (1999) 2685-2694. doi.org/10.1016/S1359-6454(99)00129-9 